\title{
A RELAÇÃO SOCIEDADE/NATUREZA E OS IMPACTOS SOCIOESPACIAIS DA INSTALAÇÃO DA FERROVIA DE INTEGRAÇÃO OESTE-LESTE (FIOL) NO MUNICÍPIO DE IBIASSUCÊ - BA
}

\section{The relationship between society and nature and socio-spatial impacts of the Ferrovia de Integração Oeste-Leste (FIOL) in Ibiassucê - BA}

\section{La relación sociedad/naturaleza y los impactos socioespaciales de la Ferrovia de Integração Oeste-Leste (FIOL) en el municipio de Ibiassucê - BA}

Luzia Barbosa de Oliveira ${ }^{1}$

Niuslane Alves dos Santos ${ }^{2}$

Jane Mary Lima Castro ${ }^{3}$

\footnotetext{
${ }^{1}$ Mestranda em Geografia e Bolsista pela Universidade Estadual do Sudoeste da Bahia. Licenciada em Geografia- Universidade do Estado da Bahia, Campus VI: luh.barbosa@hotmail.com.

${ }^{2}$ Especialista em Biodiversidade do Semiárido e Licenciada em Ciências Biológicas- Universidade do Estado da Bahia, Campus VI. Diretora da Divisão de Meio Ambiente de Ibiassucê-Bahia: niws_as@hotmail.com

${ }^{3}$ Mestranda em Geografia pela Universidade Estadual do Sudoeste da Bahia. Licenciada em Geografia- Universidade do Estado da Bahia, Campus VI. Professora da rede municipal e estadual de Guanambi-Bahia: janecastroo@ hotmail.com
}

\begin{abstract}
Resumo
O trabalho tem por finalidade analisar aspectos quanti-qualitativamente de ordem ambiental provenientes da construção da Ferrovia de Integração Oeste Leste (FIOL), uma vez que a ação antrópica é responsável por diversas modificações. Foi elaborado diante da leitura de documentos lavrados pela empresa responsável pela construção e um estudo in lócus, realizado através da aplicação de 41 questionários no povoado de Santo Antônio, em Ibiassucê - Bahia, e, dialogo com a população local para compreender relação que a sociedade estabelece com a natureza. O texto base é o Plano Básico Ambiental, no entanto outras fontes foram utilizadas para a construção desse texto, como artigos e texto da internet, assim como documentos elaborados pelo governo do Estado.
\end{abstract}

Palavras-Chave: Sociedade/Natureza; Espaço; Paisagem.

\begin{abstract}
The quantitative qualitative analytical purpose of the construction of the East West Integration Railroad (FIOL) is an analytical quantitative objective, since it is an anthropic action and responsible for several modifications. It was elaborated in front of the reading of documents washed by the company responsible for the construction and a study in locus, accomplished through the application of 41 unpopulated questionnaires of Santo Antônio, in Ibiassucê - Bahia, and, dialogue with a local population to see the society. with a nature. The basic text is the Basic Environmental Plan, not only sources for communication, such as articles and internet text, as documents prepared by the State Government.
\end{abstract}

Keywords: Society/Nature; Space; Landscape. 
El trabajo tiene por finalidad analítica cuantitativa cualitativa de orden ambiental de la construcción de la Ferrovía de Integración Oeste Este (FIOL), ya que es una acción antropica y responsable de diversas modificaciones. Se elaboró ante la lectura de documentos lavados por la empresa responsable de la construcción y un estudio en locus, realizada a través de la aplicación de 41 cuestionarios no poblados de Santo Antônio, en Ibiassucê - Bahía, y, diálogo con una población local para ver la sociedad. con una naturaleza. El texto base es el Plan Básico Ambiental, no más allá de fuentes para comunicación, como artículos y texto de Internet, como documentos elaborados por el gobierno del Estado.

Palabras clave: Sociedad/ Naturaleza; Espacio; Paisaje.

\section{Introdução}

É perceptível que as modificações ocorridas na natureza são frutos do trabalho humano, devido à forma com a qual o homem utiliza os recursos naturais. A exploração desenfreada feita pelo homem com o intuito de atender as necessidades socioeconômicas está provocando devastações significativas no espaço natural. Aumentando cada vez mais as discussões em torno dessa temática, diversas opiniões estão surgindo com o intuito de diminuir os impactos ambientais ocasionados por essas questões.

A natureza, provedora de matéria-prima para a humanidade, sofre com a exploração desenfreada de seus recursos. Os impactos ambientais é tema para diversas discussões em âmbito global, sendo assim é plausível uma postura analítica diante das possíveis alterações na conjuntura já referida. A interligação entre os termos desenvolvimento/sustentabilidade torna-se o centro das discussões propostas, uma vez que a transformação do espaço em muitos casos está relacionada ou condicionada por aspectos conjunturais de ordem política, econômica, ou mesmo social.

É justamente na ação econômica que se concentra a dinâmica de construção da obra de integração Oeste-Leste, uma vez que os fins de escoamento de produção de grãos, que teve grande aumento nos últimos anos, são vistos como estratégia de desenvolvimento estrutural das regiões em questão. Essa temática é uma questão atual que está sendo muito discutida por diversas mídias e pelos próprios beneficiados ou prejudicados pela construção da mesma, contudo há muitas censuras e benefícios com a instalação da FIOL. Deste modo faz-se uma análise sobre o que foi divulgada pela empresa pela mídia e comparada com a população envolvida sobre a intervenção humano no ambiente, que ocasionando impactos socioambientais.

\section{Relação sociedade e natureza}


Ao agir na natureza o ser humano, tendo em vista sua subsistência e, simultaneamente, construir seu espaço de vida, cria métodos e instrumentos para interferir na dinâmica natural e consequentemente causa alterações. Santos (2002), para estabelecer previamente a relação entre o homem e a natureza, enfatiza que a ação humana que modifica o meio ambiente, devido à apropriação do espaço natural para a construção de seu ambiente de vida.

É por demais sabido que a principal forma de relação entre o homem e a natureza, ou melhor, entre o homem e o meio, é dada pela técnica. As técnicas são conjuntos de meios instrumentais e sociais, com as quais o homem realiza sua vida, produz e, ao mesmo tempo, cria espaço. (SANTOS, 2002, p.29).

Se pensarmos do ponto de vista real, o trabalho é um processo de produção/reprodução de mercadorias. Bandeira e Floriano (2004) afirmam que:

É impossível imaginar a civilização atual sem estradas; por meio delas são transportadas as safras agrícolas e os insumos necessários para produzi-las, os insumos e produtos industriais, quase toda a produção intelectual humana impressa, notícias em jornais e revistas, máquinas, combustíveis, produtos minerais e toda espécie de coisa material que se possa imaginar que a humanidade utilize; além disso, são as principais vias de transporte de pessoas em curta e média distância. (BANDEIRA; FLORINO, 2004, p.3).

Sobre isso Carlos (2007) faz uma reflexão sobre a prática socioespacial que diz respeito ao modo pelo qual se realiza a vida na cidade, enquanto formas e momentos de apropriação do espaço como elemento constitutivo da realização da existência humana. Dessa forma, trás o espaço urbano como um elemento ativo nas relações de sociabilidades, e as relações estabelecidas transformam o modo de vida e de viver das pessoas. Sobre essa apropriação do espaço enquanto mercadoria Carlos (2007) faz,

A separação entre homem e natureza, valor de uso e valor de troca sinaliza a extensão do processo de desenvolvimento do mundo da mercadoria que embasa o processo de produção do espaço urbano, transformando-o em mercadoria valorizada pelo processo de urbanização da sociedade, e, com ele, eliminando referenciais, volatilizando relações sociais e gerando individualismo. Neste processo, a explosão da cidade produz o desabamento das referências, pois as relações sociais perdem sua base de sustentação. A cidade está alienada como o próprio homem e o espectro de cidade sobrevive ao que antes era a urbanidade. A função da habitação modifica-se profundamente: de ato social gerador de poesia, resume-se a mercadoria e nesta dimensão, torna-se coisa funcional, objeto de status. (CARLOS, 2007, p. 50) 
Essa abordagem feita pela autora permite estabelecer uma relação entre a implantação das ferrovias no Brasil, à modificação da paisagem em áreas naturais afastadas e do próprio centro urbano, que redefinirá e reestruturará suas atividades em função dessas novas atividades. Paula (2000) assegura que, antes de surgirem às ferrovias no Brasil, o transporte era realizado por estradas de chão do local onde a mercadoria era produzida até os portos, sendo realizado de maneira precária. Logo após a construção dessas ferrovias, estimularia o escoamento da produção com mais rapidez, tornando o mercado mais fluido.

Como Almeida; Souza; Santana (2011, p. 17) dizem “[...] a ferrovia não é uma opção da comunidade, nem de nenhuma outra localizada ao longo da mesma, mas uma imposição externa, pautada em uma lógica insustentável para aqueles que vivem do trabalho e voltada aos interesses totalmente externos aos locais". Coloca-se aqui a natureza como mercadoria e a tornam produto numa dinâmica capitalista exploradora.

Nada obstante, Santos (1988) faz uma relação entre paisagem e produção, cuja forma produtiva necessita de um tipo de instrumento de trabalho. Se os instrumentos de trabalho estão ligados ao processo direto da produção, isto é, à produção propriamente dita, também o estão à circulação, distribuição e consumo. Nesse sentido, a paisagem se organiza segundo os níveis destes, na medida em que as exigências de espaço variam em função dos processos de produção e ao nível de capital, tecnologia e organizações correspondentes.

Ao comparar com a problemática da pesquisa de modificação do espaço a partir da instalação de um projeto de transporte como a FIOL, optou-se por trabalhar com a categoria geográfica paisagem, cujos impactos são mais visíveis para análise. Santos (1988) explica,

\footnotetext{
A paisagem não se cria de uma só vez, mas por acréscimos, substituições; a lógica pela qual se fez um objeto no passado era a lógica da produção daquele momento. Uma paisagem é uma escrita sobre a outra, é um conjunto de objetos que têm idades diferentes, é uma herança de muitos diferentes momentos. Daí vem à anarquia das cidades capitalistas. (SANTOS, 1988, p, 23).
}

Assevera-se nesse momento o porquê dessa análise, exige um conflito sobre o que é paisagem, se ela é apenas natural, ideia essa errônea, visto que paisagem é tudo que a visão pode enxerga ao seu redor. Seguindo essa lógica, a cidade, o campo, e a própria natureza são paisagens que sofreram ou sofrem influência humana em maior ou 
menor escala. Essa dinâmica da paisagem, no município de Ibiassucê - BA se estabeleceu numa relação entre a construção de uma obra de grande porte, e a produção e transformação espaço urbano/rural do município, gerando novas relações com outras cidades.

Criaram-se novos serviços, novas ofertas de empregos, novas formas de comercialização e atrativo para a cidade, ocasionando o processo de migração de trabalhadores e à produção do espaço, enquanto processo de reprodução social. Diante dessa perspectiva, Lefebvre (2000) faz uma análise da dialética do espaço, ponderando sobre as contradições presentes no espaço-mercadoria, numa abstração que se concebe enquanto mundial a partir do consumo do espaço, uma vez que o espaço é considerado um campo de possibilidades de construção de um espaço diferencial, que se opõe ao homogêneo e contempla o uso.

\section{Aspectos socioeconômicos da FIOL e o município de Ibiassucê}

A construção da FIOL na Bahia trará inúmeros benefícios no que se diz respeito à economia. No caminho da ferrovia existem culturas diversas, com dinâmicas singulares e trará desenvolvimento para municípios. Pode-se destacar o Oeste-Baiano o maior produtor de soja do Norte-Nordeste e o segundo produtor de algodão do país. Promovera um grande desenvolvimento econômico no estado da Bahia e principalmente no território de identidade o Sertão Produtivo, composto por 20 municípios. Ibiassucê faz parte do território de identidade, um dos maiores polos de mineração do país e fruticultura da Bahia, espera-se que esse novo meio de transporte escorra cerca de 20 milhões de toneladas de ferro ao ano, e que traga melhorias no processo produtivo e no escoamento da produção com a estruturação do Complexo Logístico Porto Sul, da Zona de Apoio Logístico (ZAL) e da Zona de Processamento de Exportação (ZPE).

A construção da Ferrovia de Integração Oeste-Leste (FIOL) é uma obra que ocasionará diversos benefícios para a região. De acordo com a Oikos (2009), os melhoramentos são o aumento na geração de empregos, em que ocorrerá o recrutamento de mão de obra local não especializada. Oikos (2009) reforça que, os impactos negativos são o efeito barreira, devido às modificações na vegetação podendo causar alterações, como no comportamento e na reprodução destes animais. Há possibilidade de alterar significativamente as condições de vida das comunidades as quais a ferrovia vai passar, logo que a mesma atravessa áreas rurais e áreas afastadas de cidades e vilas. 
Tal situação poderá conduzir à necessidade de desapropriação local, e acarretar modificações na utilização do solo e na condução de pessoas.

A FIOL tem como objetivo principal, segundo o RIMA da empresa, interferir na matriz de transportes brasileiros, substituindo, quando possível, o transporte rodoviário pelo transporte ferroviário nas trocas de cargas entre o Oeste, o Centro, e o Leste do país. Neste mesmo sentido, a FIOL também acumula funções essenciais: é uma ferrovia voltada para exportação, interligando o Norte (Tocantins), o Centro (Goiás) e o Nordeste (Bahia). É uma ferrovia voltada ao mercado interno: FIOL também proporcionará o desenvolvimento interno, à medida que ofereça custos menores para as trocas dos produtos regionais.

Um empreendimento deste, além de gerar crescimento econômico e desenvolvimento social acaba por deixar marcas na natureza. Neste sentido o trabalho fez uma análise sobre os principais impactos negativos no município de Ibiassucê. Em relação aos impactos atribuídos a realização de obras desse porte, tendo como base as rodovias, Bandeira e Floriano (2004) abordam que, "Seus impactos iniciam no planejamento, continuam na fase de implantação e a construção, até a fase operacional, quando a qualidade de sua manutenção tem grandes implicações" (BANDEIRA; FLORIANO, 2004, p. 3). Sendo assim, é possível fazer uma relação entre os impactos causados pela construção de uma rodovia e os causados pela implantação da linha férrea, ambos geram conflitos locais, tanto nos quesitos ambientais quando socioeconômicos.

Contudo os possíveis impactos ambientais, segundo a empresa, serão justificados pelos inúmeros benefícios com a instalação da ferrovia. De modo geral, serão muitos impactos, entre eles podemos destacar o desmatamento de áreas que estão na trajetória de construção, na qual as espécies nativas serão extraídas, os terrenos serão cortados, os rios e lagos serão aterrados ou desviados de seu curso natural. De acordo com a Resolução do Conselho Nacional do Meio Ambiente - CONAMA 01/1986, Impacto Ambiental consiste em,

Qualquer alteração das propriedades físicas, químicas e biológicas do meio ambiente resultante de atividades humanas que, direta ou indiretamente, afetem a saúde, a segurança e o bem-estar da população; as atividades sociais e econômicas; a biota; as condições estéticas e sanitárias do meio ambiente e a qualidade dos recursos ambientais. (Resolução do CONAMA n. ${ }^{\circ} 01$ de 23/01/86). 
Porém, segundo Saraiva (2010), esse conceito é muito amplo: pode abranger desde uma simples brisa até a explosão de uma bomba atômica, pois ambas alteram as propriedades do ar. Então a autora afirma que, "o que caracteriza o impacto ambiental, não é qualquer alteração do ambiente, mas alterações que provoquem o desequilíbrio das relações constitutivas do ambiente, tais como as alterações que excedam a capacidade de absorção do ambiente considerado" (SARAIVA, 2010, p.13).

Se tratando das ferrovias, a Resolução CONAMA n 349, de 16 de agosto de 2004, publicada no Diário Oficial da União n ${ }^{\circ}$ 158, de 17 de agosto de 2004, Seção 1, páginas 70-71, "Dispõe sobre o licenciamento ambiental de empreendimentos ferroviários de pequeno potencial de impacto ambiental e a regularização dos empreendimentos em operação.” A Resolução CONAMA 349/2004 consiste em:

Art. 1o Estabelecer critérios e procedimentos para:

I - o licenciamento ambiental das obras ferroviárias de pequeno potencial de impacto ambiental, conforme previsto no $\S 1 \mathrm{o}$, art. 12, da Resolução CONAMA no 237, de 1997;

II - a regularização ambiental dos empreendimentos ferroviários em operação até a data de entrada em vigor da presente Resolução, mediante o competente processo de licenciamento ambiental corretivo. (Resolução do CONAMA nº 349 de 16 de agosto de 2004). 18

Conforme Oliveira Filho (2004, p. 10), “O objetivo de se estudar os impactos ambientais é o de avaliar as consequências de algumas ações, para que possa haver a prevenção da degradação de determinado ambiente, que poderá sofrer na execução de certos projetos ou ações". Acerca dos impactos ambientais, Loyola G. (1997) escreve:

Desde a aparição dos diferentes problemas ambientais estes têm recebido uma grande atenção por parte dos economistas. Esta preocupação tem levado a promover várias formas de como ajudar na conservação e preservação dos recursos naturais e ambientais através dos diferentes instrumentais econômicos. (LOYOLA G., 1997, p.1).

De acordo com Loyola (1997, p. 8), "Esta lógica do crescimento dá origem a desperdícios, degradações do meio ambiente e faz desaparecer raridades. Por exemplo, bens como a água e o ar que antes eram abundantes agora é necessário produzi-los mediante a reciclagem, e isso tem um custo alto".

Em 2012 teve início a construção da Ferrovia de Integração Oeste-Leste, com o objetivo de interligar o Estado da Bahia aos principais polos do País utilizando a Ferrovia Norte-Sul. No Relatório de Impacto Ambiental - RIMA, a Oikos (2009, p. 7) 
salienta que: "A Ferrovia de Integração Oeste-Leste, com cerca de $1.500 \mathrm{~km}$ de extensão, atravessa os Estados do Tocantins, de Goiás (apenas o extremo Nordeste do município de Campos Belos) e da Bahia”.

A Oikos (2009), afirma que o impacto ambiental é sempre coligado a um dano no meio ambiente. Porém o impacto ambiental pode ser tanto negativo como também positivo, trazendo ou não benefícios para a natureza e/ou pessoas, sendo que dentre os possíveis impactos ambientais provocados pela implantação da FIOL pode-se citar quanto aos positivos, dinamização econômica, geração de empregos para a mão de obra local não especializada, a redução do número de acidentes nas rodovias e economia nas emissões de gases do efeito estufa. Enquanto aos negativos pode-se citar o desmatamento, alterações de comportamento dos animais silvestres, alterações no uso do solo e deslocamento de pessoas.

Levando em consideração que uma das formas de se conservar e preservar o meio ambiente é através das medidas mitigadoras, a Oikos (2009) no RIMA da FIOL apresenta dentre outras medidas, o programa de plantios compensatórios, coletando sementes para a produção de mudas para posterior plantio, o programa de apoio a áreas de conservação da natureza e programas de proteção da flora e da fauna.

Se tratando do equilíbrio ambiental, Muggler; Sobrinho; Machado (2006) assegura que o meio ambiente é composto de diversos elementos, sendo que todos são importantes no estabelecimento do equilíbrio do mesmo. Quando um determinado componente deste meio é afetado, os demais têm o seu funcionamento prejudicado ou até interrompido, pois estabelecem entre si uma relação de independência. Portanto, tratando-se de preservação e conservação, é indispensável que se busque o conhecimento e a compreensão de todos, além da busca pela valorização de maneira igual dos próprios.

\section{Ponderações da população sobre os impactos ambientais da instalação da ferrovia}

Os impactos ambientais consistem em alterações das propriedades físicas, químicas ou biológicas do meio ambiente causadas por atividades humanas e podem afetar diretamente ou indiretamente a saúde, a segurança e o bem-estar da população. Desta forma, o presente trabalho foi realizado no intuito de pontuar os impactos ambientais negativos identificados pelos habitantes do povoado Santo Antônio 
relacionados à Implantação da Ferrovia de Integração Oeste-Leste (FIOL), local que concentrou a maior parte da obra no município de Ibiassucê-Ba.

Apesar da extensa área da FIOL, focou-se no traçado da ferrovia no município de Ibiassucê, vale ressaltar que o questionário foi aplicado no Povoado de Santo Antônio, por se tratar da comunidade de maior proximidade da construção da FIOL. Com base de imagem de satélite foi feita a carta imagem do município, figura 1 , na qual é possível observar o local que a ferrovia irá passar, as obras começaram a abrir o caminho para a etapa posterior, a instalação dos trilhos que ainda não foi concluída. Ainda na imagem é possível analisar a proximidade do traçado da ferrovia com a sede da cidade (o ponto destacado mostra o centro da cidade, especificamente a prefeitura), cortando a BR 030 na entrada da cidade sentido a município de Caculé. Como a maior parte da obra fica no povoado de Santo Antônio, o quadrado azul da imagem vem representando a localidade, a aproximadamente $10 \mathrm{~km}$ da sede.

Figura 1- Carta imagem da localização da ferrovia no município de Ibiassucê

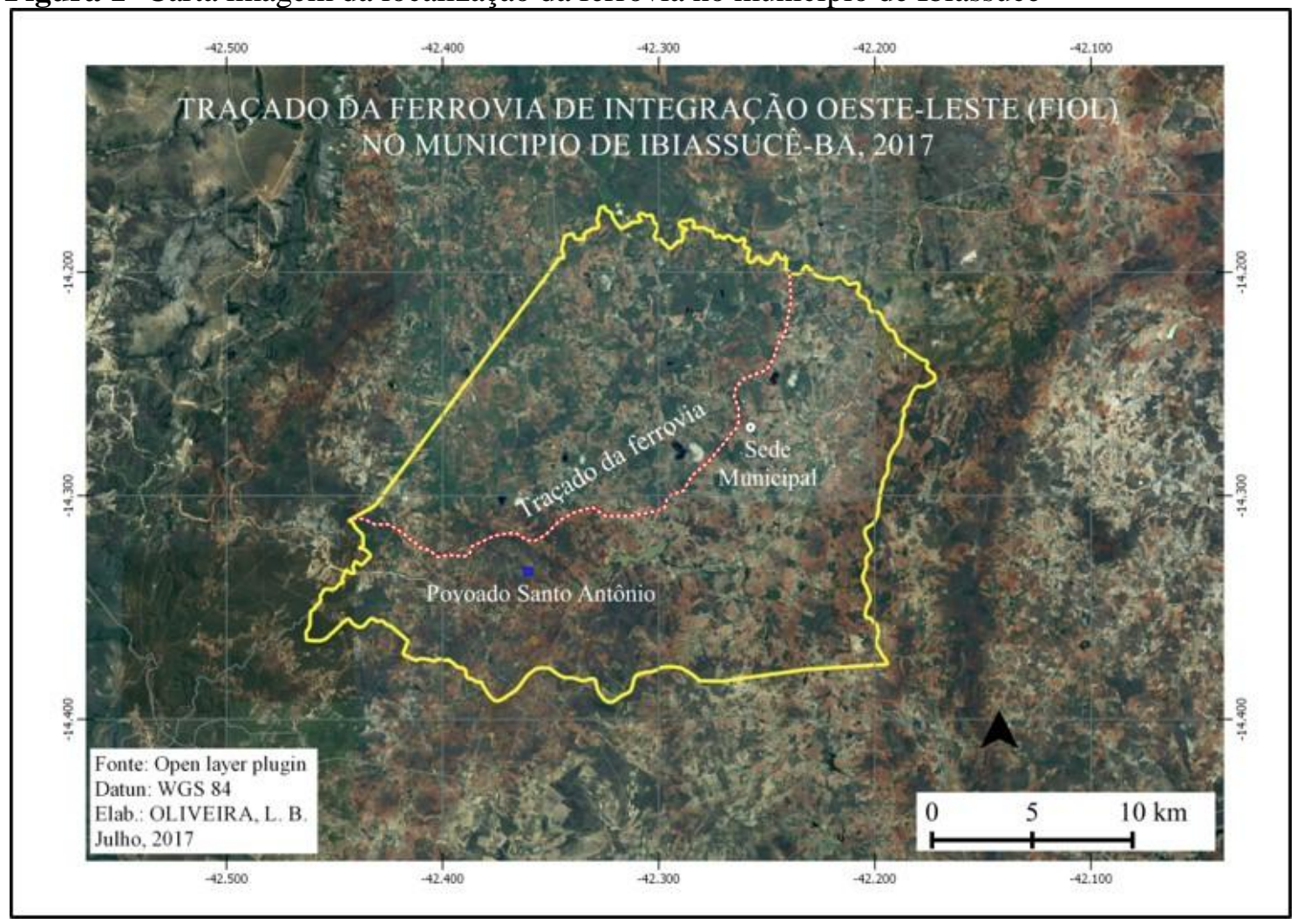

Fonte: OLIVEIRA, L. B. Julho 2017

Desta forma, os moradores deste povoado, tornaram-se agentes contribuintes para análise das questões reais do local de estudo. São, consequentemente, observadores diários da modificação ambiental, sentem, observam e identificam os processos de 
impacto ambiental com a implantação da ferrovia. Primeiramente, foi explicado a cada participante sobre os propósitos da pesquisa e sobre o termo de consentimento livre e esclarecido, possibilitando liberdade de escolha e preservação de identidade. Desta forma, integrantes do povoado de Santo Antônio foram convidados para contribuir no desenvolvimento da pesquisa, através do preenchimento do questionário.

Visando compreender os impactos da implementação de uma obra desse porte no município, foi feita a observação do local e uma pesquisa de campo com a população. Os dados foram coletados através da aplicação de questionários e diálogos com a população, composto por 03 perguntas de múltipla escolha ligadas à construção da FIOL - Ferrovia de Integração Oeste-Leste. Sendo que a primeira pergunta voltavase para desvendar qual o entendimento da polução sobre impacto ambiental; A segunda mais direta, objetivando saber quais eram os impactos ambientais provocados pela implantação da Ferrovia de Integração Oeste-Leste; E a última, na perspectiva de descobrir, na percepção dos moradores, o que poderia ser feito para diminuir os efeitos negativos provocados pela implantação da Ferrovia de Integração Oeste-Leste.

O questionário foi aplicado no dia 07 de Julho de 2013, totalizando uma amostra de 41 entrevistas, somente com o público adulto. A partir dos questionários obtidos, foi realizada análise, tabulação e interpretação dos dados. Para tabulação e confecção de gráficos foi utilizado o programa Office - Excel (2007). Em seguida, baseou-se na análise descritiva quantitativa e associação/relação com referências bibliográficas gerais e específicas. Contudo atualizou-se as informações mediante as inúmeras situações que ocorreram nessa obra, como demissão em massa, embargo da obra, atrasos de pagamento, escândalos públicos e atualmente a crise econômica na qual o país está emerso. Com a paralisação da obra existem trechos que não foram finalizados e nem se tem perspectiva. Contudo apesar destas questões de logísticas que envolvem a instalação o foco da pesquisa se mantém em entender as relações que a população começou a estabelecer a partir da modificação da paisagem local por conta dessa obra do governo.

Para obtenção da opinião popular foi elaborada com questionário, contendo questões objetivas, e aplicados com 41 pessoas que residiam no povoado Santo Antônio, local que fica próximo as obras da ferrovia. No questionário as respostas de múltipla escolha que a população poderia marcar destacando o que entenderiam por impacto ambiental: a) Prejuízo para a natureza e/ou pessoas; b) Alteração no meio ambiente que causa apenas efeitos positivos; c) Mudanças no clima de uma determinada 
região; d) Alteração no meio ambiente que pode causar tanto efeitos negativos, como também positivos; e) Mudança provocada somente por atividades de mineração; e f) Não sei. Os resultados apontaram que há uma grande dificuldade dos entrevistados em conceituar impacto ambiental, fazendo-o de maneira reducionista.

Sobre os dados obtidos referentes à primeira questão, que aborda o conceito de impacto ambiental segundo os entrevistados do povoado Santo Antônio em Ibiassucê BA, pode-se constatar que se tratando do conceito de impacto ambiental, a maioria dos entrevistados, um total de $54 \%$ entende impacto ambiental como alteração no meio ambiente que pode causar tanto efeitos negativos quanto positivos. O que leva a entender que muitos dos entrevistados consideram o impacto ambiental como uma modificação que traz apenas efeitos negativos, enquanto uma quantidade ainda maior não sabe nem o que significa este termo. Visto que $17 \%$ dos entrevistados consideram impacto ambiental somente como prejuízo para a natureza e/ou pessoas, enquanto o restante, $2 \%$, responderam que impacto ambiental corresponde apenas como uma mudança no clima de uma determinada região. No entanto, $27 \%$ não souberam conceituar impacto ambiental.

Apesar de uma quantidade significativa dos entrevistados não saber conceituar impacto ambiental, a maioria destes identificou os impactos negativos que observam no povoado, causados pela implantação da Ferrovia de Integração Oeste-Leste. Com a implantação da FIOL, os entrevistados descrevem que a população de Santo Antônio, em geral, padece em decorrência destes impactos ambientais negativos. Pois, muitas famílias tiveram que deixar suas terras, onde trabalhavam com a agricultura e/ou pecuária para que os trilhos da ferrovia passassem por este local, puderam até comprar alguns bens valiosos, mas não tinham mais terras onde cultivar e/ou criar os seus rebanhos. As estradas cheias de buraco, poeira, acabavam fazendo com que as pessoas nem pudessem usufruir de seus veículos, atrapalhando o deslocamento das pessoas, colocando em risco a população do povoado. Na figura 2 é possível observação a modificação da paisagem para a construção da ferrovia. 
Figura 2 - Fotografias da implantação da ferrovia no povoado de Santo Antônio

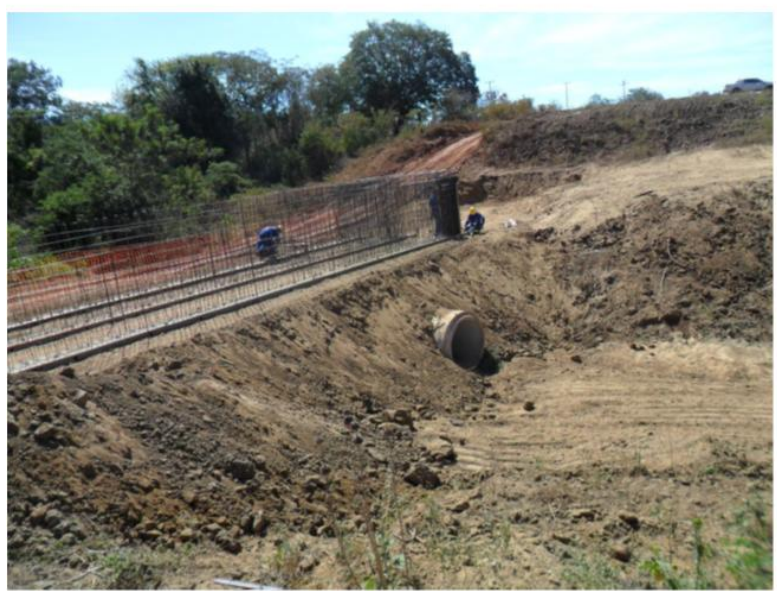

A

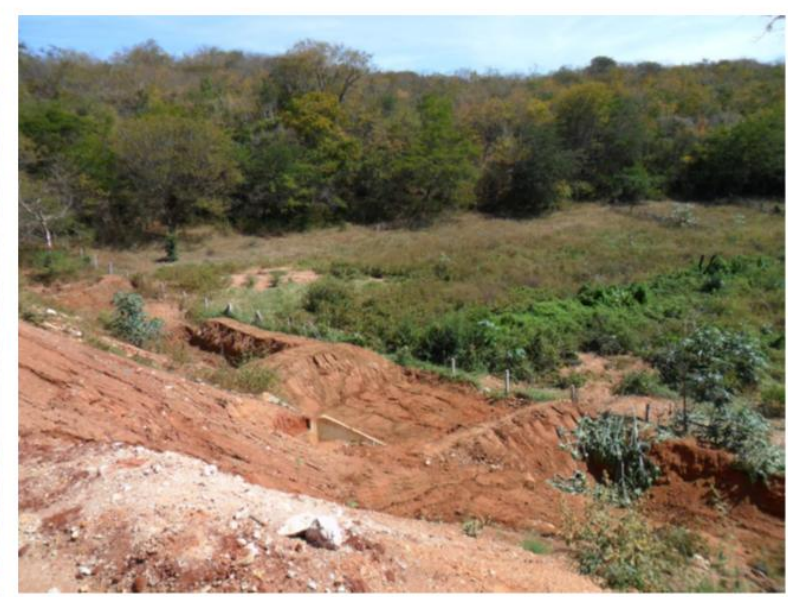

B

Fonte: SANTOS, N. A. Pesquisa de campo, Julho de 2013.

A figura 2A mostra funcionários trabalhando, abaixo está um túnel para o escoamento de águas da chuva; e a 2B ilustra a criação de bacias, para evitar erosões que poderão causar uma invasão na faixa de domínio.

A respeito da percepção social Mucelin e Bellini (2008, p. 116), mencionam que "Percepção é uma palavra de origem latina - perceptione - que pode ser entendida como tomada de consciência de forma nítida a respeito de qualquer objeto ou circunstância. A circunstância em questão diz respeito a fenômenos vivenciados". Como foi mencionado anteriormente a Resolução CONAMA 01/1986, Impacto Ambiental em qualquer ação humana contra a natureza que direta ou indiretamente afetam a população e diminuem a qualidade e quantidade de recursos naturais.

Então, a população de Santo Antônio passa a obter percepção de que em seu território estão ocorrendo mudanças no ambiente. A maioria dos entrevistados mencionaram três impactos ambientais negativos, podendo ocorrer desde a construção até a implantação da ferrovia. No que trata sobre as medidas mitigadoras listadas pelos entrevistados do povoado Santo Antônio para diminuir os efeitos dos impactos negativos provocados pela implantação da FIOL, um total de vinte e seis entrevistados apontaram quatro alternativas: a coleta de sementes para a produção de mudas e posterior plantio nas áreas desmatadas; a construção de passagens inferiores que possibilitem a passagem de animais de um lado para outro; a garantia de um bom nível de comunicação entre os responsáveis pela ferrovia e os moradores da região; e fazer com que a implantação da ferrovia não prejudique o funcionamento de estradas.

No questionário, última questão tratava sobre medidas mitigadoras listadas pelos habitantes do povoado Santo Antônio para diminuir os efeitos dos impactos negativos 
provocados pela implantação da Ferrovia de Integração Oeste-Leste na região. Para dá suporte à resolução da questão foi coloca as seguintes medidas: a) Coleta de sementes para a produção de mudas de plantas e posterior plantio nas áreas desmatadas; b) Construção de passagens inferiores que possibilitem a passagem de animais de um lado pro outro. c) Garantir um bom nível de comunicação entre os responsáveis pela ferrovia e os moradores da região; d) Fazer com que a implantação da ferrovia não prejudique o funcionamento de estradas; e) Nada pode ser feito; e f) Não sei. Os dados mostram que $63 \%$ dos entrevistados elencaram quatro medidas mitigadoras impactos de ambientais, $32 \%$ elencou três alternativas mitigadoras, $3 \%$ não souberam ou não quis opinar. E dos entrevistados, apenas $2 \%$ elencaram duas possibilidades para amenizar os impactos ambientais decorridos da construção da ferrovia na localidade, como a coleta de sementes para a produção de mudas e posterior plantio nas áreas desmatadas, e fazer com que a implantação da ferrovia não prejudique o funcionamento de estradas.

Da mesma forma como na questão anterior, apesar de um número significativo de entrevistados não conceituarem Impacto Ambiental, a maioria soube indicar medidas mitigadoras. Um maior número de entrevistados soube indicar medidas que podem diminuir os efeitos causados pelos possíveis danos ao meio ambiente causados pela construção da FIOL nesta localidade. A população, ao saber do que precisa ser feito para minimizar os danos à natureza e/ou pessoas, pode atuar como um agente fiscalizador, cobrando o que é dela e da natureza por direito. É compreendendo a relação do ser humano com a natureza, que podemos nos colocar como indivíduos conscientes, tornando nos responsáveis pelo planeta em que vivemos.

Jacobi (2003) menciona que quando se trata de sustentabilidade acabamos nos deparando com os termos "sociedade de risco", e ao nos depararmos com esta situação, precisamos aumentar o número de prática para a sociedade no intuito de fortalecer a informação no que diz respeito à educação ambiental. Desta forma, há certa compreensão e identificação de impactos ambientais negativos e medidas mitigadoras pelos entrevistados. Por outro lado, trabalhos educacionais podem melhorar e ampliar o entendimento e a postura dos cidadãos diante de tais questões ambientais.

De acordo com a análise dos questionários verificou-se que conceituar impacto ambiental não é tarefa fácil. Mesmo que essa problemática ambiental esteja evidente no cotidiano e nos meios de comunicação dos entrevistados ainda é difícil, pois se trata de um termo abrangente, com uma diversidade de conceitos. Uma quantidade acentuada de entrevistados, $17 \%$, conceitua impacto ambiental como apenas prejuízos para a natureza 
e/ou pessoas, ou seja, de maneira reducionista. E 27\%, uma quantidade ainda maior, desconhece este termo. A maioria sabe identificar quais são os possíveis impactos ambientais negativos que uma determinada construção pode causar à natureza e/ou aos seres humanos, este valor corresponde a $54 \%$ dos entrevistados. Os entrevistados também sabem identificar as medidas mitigadoras dos mesmos. No entanto, ainda existe dificuldade de um número acentuado em compreender alguns termos vinculados ao meio ambiente, talvez, estando associado ao nível de escolaridade da população entrevistada, considerando-se que é um nível baixo.

\section{Considerações finais}

A Geografia é uma ciência moderna, que atravessou diferentes caminhos e teve diferentes definições. Atualmente, entende-se a Geografia, como a ciência que estuda o espaço geográfico, isto é, aquele habitado pelo homem e de interesse para este, tanto em seus aspectos naturais quanto em seus aspectos humanos. $\mathrm{O}$ espaço geográfico deve ser analisado, explicado e compreendido a partir da relação sociedade-natureza, na qual a reprodução deve ser vista numa perspectiva de reprodução socioespacial. Sendo a construção do espaço é motivada pela necessidade histórica social, sua face visível é materializada pelo território resultado de ações/poder.

No início desse processo, há abundância de recursos naturais e de mercados a serem explorados sem a preocupação com projeções de esgotamento de insumos, de demandas. Dessa forma, a transição de padrões consumistas para opções mais conscientes, sustentáveis, implica re (construir) culturalmente lógicas, representações e significados do consumo e seus efeitos. Nessa perspectiva, o apelo da sustentabilidade traz imbricado em si a noção de responsabilidade dos indivíduos perante os usos dos recursos ambientais no presente e seus efeitos posteriores, emergindo a necessidade de construir visões de futuro. Segundo Cavalcanti (1996) a transformação desses comportamentos é complexa, pois a evolução e a história do homem mostram que os vencedores são as espécies e sociedades que agem mais rápido e consomem mais energia e materiais de alta qualidade.

Então, considera-se que termos vinculados ao meio ambiente devem fazer parte de um trabalho constante que promova a sustentabilidade por parte da sociedade em relação ao uso dos recursos naturais. Uma Educação Ambiental que proporcione uma conexão que tem como centro a consciência ambiental, tornando os indivíduos 
responsáveis por construir uma sociedade comprometida com a natureza é de extrema importância.

\section{Referências}

ALMEIDA, Miriam Cléa Coelho; \& SOUZA, Suzane Tosta; \& SANTANA, Mário Rubem Costa. O traçado da ferrovia de integração oeste-leste (FIOL) e os impactos sócio-espaciais no município de Tanhaçú-BA. ANAIS do VIII Encontro Baiano de Geografia e X Semana de Geografia da UESB. Agosto de 2011. ISSN 2179-4774. Disponível em <http://www.uesb.br/eventos/ebg/?pagina=anais > acesso em junho de 2017.

BANDEIRA, Clarice; FLORIANO, Eduardo Pagel. Avaliação de impacto ambiental de rodovias. Associação de Pesquisa, Educação e Proteção Ambiental do Noroeste do Estado Do Rio Grande Do Sul, Santa Rosa n ${ }^{\circ}$ 8, $1^{\text {a }}$ ed p. 3-68, 2004.

CARLOS, Ana Fani Alessandri. O Espaço Urbano: Novos Escritos sobre a Cidade. São Paulo: Labur Edições, 2007, 123p.

CAVALCANTI, Clóvis. Condicionantes biofísicos da economia e suas implicações quanto à noção do desenvolvimento sustentável. In: ROMEIRO, Ademar Ribeiro; REYDON, Bastian Philip; LEONARDI, Maria Lucia Azevedo (Orgs.). Economia do meio ambiente: teoria, políticas e a gestão de espaços regionais. Campinas: UNICAMP/IE, 1996. p. 61-82.

JACOBI, P. Educação Ambiental, Cidadania e Sustentabilidade. Cadernos de Pesquisa, $\mathrm{n}^{\circ}$ 118, p. 189-205. Disponível em: 〈http:www.scielo.br〉. Acesso em: 12 Jul. 2013.

LEFEBVRE, Henri. La production de l'espace. 4e éd. Paris: Éditions Anthropos, 2000. (Original La production de l'espace. Paris: Anthopos, 1986)

LOYOLA G., Roger. A Economia Ambiental e a Economia Ecológica: Uma Discussão Teórica. Disponível em: <http: www.ecoeco.org.br>. Acesso em: 02 Fev. 2012.

MUGGLER, Cristine Carole; SOBRINHO, Fábio de Araújo Pinto; MACHADO, Vinícius Azevedo. Educação em Solos: Princípios, Teoria e Métodos. Ensino da Ciência do Solo, Viçosa, vol. 30, n 4, p. 733-740. Disponível em <http: www.scielo.com.br>. Acesso em: 02 Fev. 2012

OIKOS PESQUISA APLICADA. Relatório de Impacto Ambiental. Disponível em < http://www.oikos.com.br/site_ok/FIOL.htm>. Acesso em: 13 Ago. 2012.

OLIVEIRA FILHO, Jaime E. Gestão Ambiental e Sustentabilidade: Um Novo Paradigma Eco-Econômico para as Organizações Modernas. Disponível em: <http: www.fbb.br>. Acesso em: 02 Fev. 2012.

PAC. Ferrovia de Integração Oeste-Leste é vistoriada por ministros. Disponível em <http://www.pac.gov.br/noticia/e4bb2029> ás 15:37 do dia 19-07-12. 
PAULA, Dilma Andrade. As ferrovias no Brasil: análise do processo de erradicação de ramais. In: II Congresso de História Ferroviária. Anais. UAM: Madrid, 2001.

REVISTA BAHIA DE TODOS OS CANTOS. Governo do Estado. N ${ }^{\circ} 4$ Ano 2 Março 2010.

SANTOS, Milton. Metamorfoses do espaço habitado, fundamentos teórico e metodológico da geografia. Hucitec. São Paulo 1988.

SANTOS, Milton. A natureza do espaço: Técnica e Tempo, Razão e Emoção São Paulo, 4. ed. 2. reimpr. - São Paulo: Editora da Universidade de São Paulo, 2006.

SARAIVA, Danieli. Impactos Ambientais Causados pela Expansão Urbana no Município do Rio de Janeiro. 2010. 45 f. Monografia (Pós-Graduação "Lato Sensu" em Engenharia de Produção)-Universidade Candido Mendes, Rio de Janeiro, 2010.

Recebido em: 18/11/2017

Aceito para publicação em: 10/12/2017 